\title{
RENAL BIOPSY IN PAEDIATRIC POPULATION
}

\author{
AHMAD ZEB KHAN ${ }^{1}$, RIAZ GUL ${ }^{2}$, AZIZ AHMAD ${ }^{3}$ \\ 1. Department of Nephrology, Post Graduate Medical Institute, Lady Reading Hospital, Peshawar. \\ 2. Department of Community Medicine, Ghandara Medical College, \\ 3. Department of Medicine, Saidu Medical College, Swat.
}

\begin{abstract}
OBJECTIVE: To find out the pattern of glomerulopathies in paediatric population, undergoing renal biopsy at Khyber Teaching Hospital, Peshawar.

METHODS: This was a prospective study carried out at the department of Nephrology at Khyber Teaching Hospital, Peshawar from June 2010 till June 2012. Ultrasound guided percutaneous renal biopsies were carried out in patients with the finding of; 1) Nephrotic range proteinuria in children. 2) Non-Nephrotic range proteinuria with evidence of hypertension / haematuria / deranged renal function or active sediments on urine microscopy. 3) Steroid resistant nephrotic syndrome in children (patients not responding to steroid in eight weeks time) and 4) Children with nephrotic syndrome who were not tolerant of steroid therapy or were considered for immunosuppressive drugs.

RESULT: A total of 155 renal biopsies were done. Out of these 90 were male patients and 65 were females. The most common histopathological lesion among children population was minimal change disease $(42.66 \%)$ followed by focal segmental glomerulosclerosis $(25.33 \%)$ and membranous GN $(16.0 \%)$. We observed that nephrotic range proteinuria was most prevalent in minimal change disease and membranous GN followed by focal segmental glomerulosclerosis. While non-nephrotic range proteinuria was mostly seen in patients with membranoprolifirative GN.

CONCLUSION: In paediatric population, minimal change disease is the most common encountered glomerulopathy, followed by focal segmental glomerulosclerosis and membranous GN.
\end{abstract}

KEY WORDS: Nephrotic syndrome, Renal biopsy, Proteinuria, Glomerulopathy

\section{INTRODUCTION}

Glomerulonephritis (GN) is a relatively rare disease with numerous subtypes. Most regional nephrology centers see only a limited number of patients with each type of GN every year. Information about the prevalence and incidence of $\mathrm{GN}$ in the general population is rather scarce; comprehensive epidemiological surveys are difficult to undertake, especially since the onset of most cases of GN is 'silent' so the diagnosis is often incidental, made by urine testing during a routine medical examination.

Evaluation of pathogenic features identified in a renal biopsy specimen may be required for definitive diagnosis. In patients with renal disease, renal biopsy provides tissue that can be used to determine the cause, predict the prognosis, and direct the treatment. Renal tissue obtained by biopsy has contributed enormously to the field of Nephrology.

Percutanous biopsy needle from Menghini needle, Vim Silverman and its Franklin modification (Trucur), to automated spring loaded gun have increased the yield of successful biopsies $60 \%$ to $90 \%$ with associated minimal complications.

Percutanous renal biopsy (PRB) was introduced in early 1950 s and since then, with the advancement of imaging technique and biopsy needles, the procedure has been simplified with improved success rate.Now a days the PRB is a relatively safe procedure with life threatening complications occurring in $<0.1 \%$ of biopsy ${ }^{1,2,3,4}$ and diagnostic yield of $>96 \%{ }^{\prime}$. 
Recently there has been a major shift towards utilization of spring- loaded disposable gun devices. In addition to percutaneous and open renal biopsy, transjugular and even laparoscopic renal biopsies are being carried, where indicated.

Renal biopsy is indicated in a patient with renal disease when all the three following conditions are met;

1) The cause cannot be determined or adequately predicted by less invasive diagnostic procedures.

2) The signs and symptom suggest parenchymal disease that can be diagnosed by pathological evaluation.

3) The differential diagnosis includes diseases that have different treatments, and different prognosis.

The standard of care after renal biopsy includes close observation and bed rest for 24 hours following the procedure. With ever increasing safety profile of renal biopsy, in selected group of patients the procedure can be performed on outpatients basis by experienced nephrologists and patients can be discharged only after 6 to 8 hours of observation $^{5,6,7}$

\section{METHODS}

This retrospective study was out in the Department of Nephrology at Khyber Teaching Hospital Peshawar. Over a period of 3 years (June 2001 till June2004). A total of 155 renal biopsies were performed during this period in children glomerulopathies in paediatric population (age less than 12 year) having significant proteinuria due to renal disease, we used strict inclusion and exclusion criteria, as per following details.

\section{Inclusion criteria;}

- Nephrotic range proteinuria in children.

- Non-nephrotic range proteinuria with evidence of hypertension / haematuria/ deranged renal function or active sediments on urine microscopy.

- Steroid resistant nephrotic syndrome in children (patients not responding to steroid in eight weeks time)

- Children with nephrotic syndrome who were not tolerant of steroid therapy or were considered for immunosuppressive drugs.

\section{Exclusion criteria;}

- Age more than 12 years.

- Known diabetics with proteinuria (more than 5 years duration).

- Bilateral small echogenic or scared kidneys.

- Polycystic kidney and congenital nephritis.

- Typical history of proceeding throat infection followed by active sediment in urine microscopy.

- Sudden onset of simple proteinuria with normal renal functions and normal blood pressure.

All patients who met the above mentioned criteria were included in this study. Blood pressure, PT/ APTT, Platelets count, $24 \mathrm{hrs}$ urinary protein estimation, $\mathrm{HBs}$ antigen, Anti HCV antibodies and abdominal ultrasound were scrutinized of all the included cases.

Real time ultrasound guided renal biopsies were done. Spring loaded disposable percutaneous biopsy needle was used in all the patients (18G for children)

Biopsy material was fixed in 10 buffered formaline and was sent for histopathology to Agha Khan Clinical Laboratory with relevant information. Biopsy containing only tubules, interstitium and less than 5 glomeruli were considered inadequate for reporting purpose and excluded from the study.

\section{RESULTS}

A total of 155 renal biopsies, were performed during this study.Outof these,90 (58.0\%) cases were male patients while $65(41.9 \%)$ cases were females. The mean age of patients in our study was6.75 \pm 4.14 years (SD) with a range of 8 months to 12 years. The average duration of illness in this series was 3.7 months (range from 15 days to 8 months).

In this series a total of 150 out of 155 renal biopsies $(96.77 \%)$ fulfilled the inclusion criteria of the study. Regarding the indications for renal biopsy in 
this series, the commonest cause was proteinuria alone accounting for $106(70.66 \%)$ cases. The next commonest cause was proteinuria with haematurial $7(11.33 \%)$ cases, followed by proteinuria with deranged renal function 10 $(6.66 \%)$ cases, unexplained acute renal failure 9 $(6.0 \%)$ cases, and finally haematuria alone / with deranged renal function accounting for $8(5.33 \%)$ cases.

Table 1.

\section{Associated conditions with different GN}

\begin{tabular}{|l|c|c|c|c|}
\hline Types of GN & $\begin{array}{c}\text { HBs } \\
\text { Antigen +ve }\end{array}$ & $\begin{array}{c}\text { Upper Resp. } \\
\text { Tract } \\
\text { Infection }\end{array}$ & $\begin{array}{c}\text { Ventricular } \\
\text { Septal Defect }\end{array}$ & TOTAL \\
\hline Post. Inf. GN & & 5 & & 5 \\
\hline Memb.GN & 4 & & & 4 \\
\hline MCD & 1 & & 1 & 2 \\
\hline FSGS & & 1 & & 1 \\
\hline TOTAL & $\mathbf{5}$ & & & $\mathbf{1 2}$ \\
\hline
\end{tabular}

Table 2;

Proteinuria as predictor of Glomerulopathy

\begin{tabular}{|c|c|c|}
\hline \multicolumn{2}{|c|}{ Glomerulopathy } & $\begin{array}{c}\text { Proteinuria } \\
\text { (patients with }>3 \mathrm{gms} / \text { day) }\end{array}$ \\
\hline Minimal Change Disease & $(n=64)$ & $64(100 \%)$ \\
\hline Membranous GN & $(n=24)$ & $24(100 \%)$ \\
\hline F.S.G.S & $(n=38)$ & $26(68 \%)$ \\
\hline A.T.N & $(n=8)$ & $4 \quad(50 \%)$ \\
\hline Tubulointerstitial Nephrotis & $(n=8)$ & $4(50 \%)$ \\
\hline M.P.GN & $(n=8)$ & $(37.5 \%)$ \\
\hline
\end{tabular}

The most common histopathological lesion among the biopsied patients in the age group of less than $12 \mathrm{yrs}$ showed that Minimal Change Disease (MCD) was the most frequently occurring entity accounting for 64 $(42.66 \%)$ cases, followed by Focal Segmental Glomerulosclerosis(FSGS) and Membranous GN accounting for $38(25.33 \%)$ cases and $24(16.0 \%)$ cases respectively (Figure). The remaining glomerulopathied (GN) were Mesangio proliferative GN (MPGN), TubuloInterstitial Nephrotic (TIN) and Acute Tubular Necrosis ATN) each having $8(5.33 \%)$ cases.

The associated conditions, which are encountered with different glomerulopathies in this series, are summarized in table 1 .

As shown in this table 1, Five patients had HBs antigen positive status while 6 patients were having Upper respiratory tract infection, and one patient with ventricular septal defect was detected.

\section{DISCUSSION}

Renal biopsy helps nephrologists in establishing accurate diagnosis, identifying any reversible pathology, helps in devising appropriate management plan for the patient and is very useful in understanding the histological nature of the disease.

The most common histopathological lesion in paediatric population (age $<12 \mathrm{yrs}$ ) in our series is Minimal Change Disease (MCD), Focal Segmented Glomerulosclerosis and Membranous GN. This is comparable to that reported by Farida and Azhar and Noor Khan et All ${ }^{9}$. But according to Hafeez and Rasool, Mesangioprolifirative $\mathrm{GN}$ is the leading entity followed by Membranoprolifirative GN and Minimal Change Disease. ${ }^{10}$ This is probably because they also include the children who were suspected of post infective GN in there study.

Histological examination of biopsies at Mayo Hospital Lahore revealed focal Segmental Glomerulosclerosis in $12(27.9 \%)$, membranoproliferative/ mesangiocapillary glomerulonephritis in 7 (16.27\%), mesangial proliferation in $4(9.30 \%)$, and membranous nephropathy in $2(4.65 \%)$ cases ${ }^{11}$.

Two landmark studies from our Asian region also confirmed the finding of MCD as the leading cause of proteinuria in paediatric population. A large study carried out in Malsysia showed that in more than 2000 paediatric population, MCD and Membranous GNwere the leading entities in this group of patients ${ }^{12}$.

Similarly in a prospective study showing the pattern of glomerulonephritis in Singapore children, of the primary $\mathrm{GN}$ in paediatric cases, MCD was the most common $(22 \%)$ followed by focal global sclerosis.

$(20 \%)$, focal segmental glomerulosclerosis $(17 \%)$ and diffuse mesangialproliferative $\mathrm{GN}(11 \%){ }^{13}$

Regarding the presence of nephrotic range proteinuria versus non-nephrotic range proteinuria the earlier finding at Rawalpindi by Yaqoobet all ${ }^{14}$ that Membranoprolifirative GN is the leading cause of nonnephroticrange proteinuria and Membranous GN the leading cause of nephroticrange proteinuria, was also validated by similar finding in our study. It is seen that Minimal Change Disease and Membranous GN are the commonest entity with proteinuria of more than 3 $\mathrm{gm} / \mathrm{day}$, followed by focal Segmental Glomerulosclerosis and Membranoproliferative GN. (Table2).

More importantly the finding of deranged renal 
function with different glomerulopathies, we observe that both Membranous $\mathrm{GN}$ and Minimal Change Disease are rarely associated with significant renal impairment.

We did not find any significant number of Mesangio proliferative GN in this series because all those cases suspected of having post infective GN were excluded from our study. Similarly we could not show any $\lg A$ nephropathy due to the lack of immunofluorescence studies of the biopsy samples. The associated conditions which we encountered in our study did show already established fact that $\mathrm{HBs}$ antigen positive patients were more likely to have Membranous GN.

As different studies have shown, the risk of complications significantly reduces when biopsy is carried out in this series, as our team encountered no major complications during the study period.

\section{CONCLUSION}

We conclude that in children Minimal Change Disease is the most frequently encountered glomerulopathy followed by FSGS and Membranous GN.

We also conclude that percutaneous renal biopsy is a safe procedure in expert hands with minimal complication. It helps the nephrologist to find out the underlying histopathology for proper diagnosis and better management.

\section{REFERENCES}

1. Korbet SM: Percutaneous renal biopsy. Seminnephrol 22:254-267, 2002.

2. Burstein DM, Schwartz MM, Korbet S: Percutaneous renal biopsywith the use of real- time ultrasound. Am J Nephrol 11:195-200, 1991.

3. MarwatDS,KorbetSM: Timing of complication in percutaneous renal biopsy: What is the optimal period of observation? Am J Kidney Dis 28:47-52, 1991.

4. Mendelssohn DC, Cole EH: Outcomes of percutaneous Kidney biopsy, including those of solitary native kidneys. Am J Kidney Dis 26:580-585,1995

5. Fraser IR, Fairley KF: Renal biopsy as an outpatient procedure. Am J Kidney Dis 25:876-878, 1995.

6. Jones B, Puvaneswary M, Nanra R, Trevillian P, Carney S, Gillies A: A reduced duration of bed rest after percutaneous renal biopsy. ClinNephrol 35:44-45,1991.

7. SimekesAM, BloweyD,Gyves KM, Alon US: Success and safety of same-day kidney biopsy in children and adolescents. PediatrNephrol 14:946-952,2000.

8. Aziz F, Quraishi AM, Nephrotic Syndrome: Minimal change disease J Ayub Medical College Abbottabad, Dec 2001;13(4):35-40.

9. Lakhana NK, Khan H, Butt G: Renal biopsy finding in childhood Nephrosis. J Rawal Med Coll. Dec
2002;6(2):57-9.

10. Hafeez F, Rasool F, Hamid T, Renal biopsy in childhood nephrotic syndrome. J Coll Physicians Surg Pak. Aug 2002;12(8):454-7.

11. Baloch GR, Butt TK, Ahmad TM, Experience of renal biopsy in children. Pak Ped J. June 200;24(2):51-5.

12. Khoo JJ, Pee S, Thevarajah B, Yap YC, Chin CK. Biopsy prove childhood GN in Johor. Med J Malaysia. June 2004;59(2):218-25.

13. Yap HK, Murugasu B, Saw AH et al. Pattern of glomerulonephritis in Singapore children-a renal biopsy perspective. Ann Acad Med Singapore. Jan 1989;18(1):35-9.

14. Yaqoob N, Malik JM, Latif $\mathrm{N}$ et al. An audit of renal biopsies. Rawal MedJ. Sep2000;3:13-5.

15. Ori $Y$, Neuman $H$, ChagnacA et al. Using automated biopsy gun with real-time ultrasound for native renal biopsy. Isr Med Assoc J.2002 Sep; 4(9):698-701.

\section{FOR CORRESPONDENCE:}

Dr. AhmadZeb Khan (FCPS)

Assistant Professor, Department of Nephrology, Khyber Teaching Hospital Peshawar.

Cell\# 03018575722 